\title{
AÇÕES EMPREENDEDORAS E POLÍTICAS PÚBLICAS: UMA ARTICULAÇÃO PARA PROMOVER O ESPORTE
}

\author{
1 Denise Aparecida Hipólito Borges \\ 2 Mônica Carvalho Alves Cappelle
}

\section{Resumo}

Objetivo: compreender as ações desenvolvidas no esporte de Lavras/MG, para afirmar se elas podem ser consideradas empreendedoras. O propósito é entender como articular políticas públicas e ações empreendedoras na promoção do esporte nesse município.

Metodologia: o estudo seguiu uma orientação epistemológica interpretativista, apoiada na metodologia de pesquisa-ação, e utilizou, como técnica, a análise de conteúdo temática. Optou-se por uma abordagem qualitativa, com os seguintes métodos de pesquisa: entrevistas presenciais com roteiro aberto, análise documental, diário de campo e brainstorming.

Principais resultados: os resultados apontam a existência de uma ação empreendedora no contexto público, que envolve o poder público de modo particular sem, entretanto, nele ter se originado.

Contribuições teóricas/metodológicas: a abordagem da ação empreendedora para o contexto público; e a utilização da pesquisa-ação como metodologia, para os estudos sobre o empreendedorismo.

Relevância/originalidade: 0 estudo evidencia outra forma de interpretar o empreendedorismo, no contexto público, desviando o foco do empreendedor para a ação empreendedora, propriamente dita. As suas aplicações ao fenômeno estudado atestam o ineditismo da pesquisa.

Implicações sociais ou para a gestão: os achados deste estudo permitem aos gestores públicos rever suas decisões, a fim de articular ações empreendedoras e políticas públicas, na promoção de ações inovadoras no esporte.

Palavras-chave: Empreendedorismo. Ações Empreendedoras. Empreendedorismo Público. Ações Empreendedoras no Contexto Público. Esporte.

Recebido: 15/11/2019 / Aprovado: 07/04/2020

Editor responsável: Profa. Dra. Vânia Maria Nassif

Processo de avaliação: Double Blind Review

Doi: https://doi.org/10.14211/regepe.v9i4.1580

\footnotetext{
${ }^{1}$ Universidade Federal de Lavras - UFLA, Minas Gerais, (Brasil). E-mail: denisehipolito@yahoo.com.br Orcid id: https://orcid.org/0000-0001-5083-0916

2 Universidade Federal de Lavras - UFLA, Minas Gerais, (Brasil). E-mail: edmo@ufla.br Orcid id: https://orcid.org/0000-0002-0095-3405
} 


\title{
ENTREPRENEURIAL ACTIONS AND PUBLIC POLICIES: A RELATIONSHIP TO PROMOTE THE SPORT
}

\begin{abstract}
Objective: to understand the essence of the actions developed in the sport of Lavras/MG to say whether they can be considered entrepreneurial. The purpose seeks to understand how public policies and entrepreneurial activities can be articulated to promote the sport in this municipality.
\end{abstract}

Methodology: the research followed an interpretivist epistemological orientation based on the methodology of research-action using the analysis of thematic content as analysis technique. The qualitative approach and the following research methods: face-to-face interviews with open script, documentary analysis, field diary and brainstorming were chosen.

Main results: the results point to the existence of an entrepreneurial action in the public context, involving the public power in a particular way without, however, having originated in it.

Theoretical/methodological contributions: the approach of the entrepreneurial action for the public context; and the use of action research as methodology for the studies about entrepreneurship.

Relevance/originality: the study draws attention to another way of interpreting entrepreneurship in the public context by shifting the focus from the entrepreneur to the entrepreneurial action itself. Its application to the studied phenomenon attest to the originality of the research.

Implications for management or social: the findings of this study allow public managers to review their decisions in order to articulate entrepreneurial actions and public policies in promoting innovative actions in sport.

Keywords: Entrepreneurship. Entrepreneurial Actions. Public Entrepreneurship. Entrepreneurial Actions in the Public Context. Sport. 


\section{ACCIONES EMPRENDEDORAS Y POLÍTICAS PÚBLICAS: UNA ARTICULACIÓN PARA FOMENTAR EL DEPORTE}

\section{Resumen}

Objetivo: Entender las acciones desarrolladas en el deporte de Lavras/MG, para indicar si pueden considerarse emprendedoras. El propósito es entender cómo articular las políticas públicas y las acciones emprendedoras en la promoción del deporte en este municipio.

Metodología: el estudio siguió una orientación epistemológica interpretativa, sustentada en la metodología de investigación-acción, y utilizó, como técnica, el análisis de contenido temático. Optamos por un enfoque cualitativo, con los siguientes métodos de investigación: entrevistas cara a cara con guión abierto, análisis de documentos, diario de campo y lluvia de ideas.

Resultados principales: los resultados apuntan a la existencia de una acción emprendedora en el contexto público, que involucra a las autoridades públicas de una manera particular sin, no obstante, originarse allí.

Aportes teóricos/metodológicos: el acercamiento de la acción empresarial al contexto público; y el uso de la investigación-acción como metodología para los estudios sobre el espíritu empresarial.

Relevancia/originalidad: el estudio muestra otra forma de interpretar el emprendimiento, en el contexto público, desviando el enfoque del emprendedor hacia la propia acción emprendedora. Sus aplicaciones al fenómeno estudiado dan fe de la originalidad de la investigación.

Implicaciones sociales o de gestión: Los hallazgos de este estudio permiten a los gestores públicos revisar sus decisiones, a fin de articular acciones emprendedoras y políticas públicas, en la promoción de acciones innovadoras en el deporte.

Palabras clave: Emprendimiento. Acciones emprendedoras. Emprendimiento público. Acciones emprendedoras en el contexto público. Deporte. 


\section{INTRODUÇÃO}

O conceito de políticas públicas pode sofrer algumas variações, de acordo com o enfoque que Ihe for dado, contudo, o termo não costuma fugir ao fato de se tratar de ações para as quais são destinados os recursos públicos. Souza (2006, p. 26), por exemplo, resume que as políticas públicas se constituem "[...] no estágio em que os governos democráticos traduzem seus propósitos e plataformas eleitorais em programas e ações que produzirão resultados ou mudanças no mundo real". Essas ações irão proporcionar o bem-estar social, garantindo o direito de acesso da sociedade aos serviços públicos de educação, saúde, esporte e lazer, entre outros (Nogueira, 2001).

Embora a gestão pública brasileira sempre tenha sido vista como uma instituição morosa, o gerencialismo, baseado especialmente nos ideais de um governo empreendedor, possibilitou uma nova forma de se fazer políticas públicas mais eficientes (Bresser-Pereira, 2010). Assim, apesar de o empreendedorismo ter ficado durante muito tempo limitado às organizações empresariais (Valadares, Emmendoerfer, Alves, \& Morais, 2012), o fenômeno se tornou uma ferramenta interessante para as organizações públicas.

O empreendedorismo, porém, foi incorporado à administração pública com algumas particularidades do empreendedorismo tradicional, como, por exemplo, o fato de ele estar associado à imagem de um indivíduo - o governante inovador, que percebe os problemas públicos, age em momentos oportunos e toma atitudes empreendedoras, em busca de soluções (Valadares et al., 2012) -, enfatizando sobremaneira a figura do gestor público. Essa visão individualista, do empreendedorismo como o ato de um sujeito específico, proporcionou questionamentos, sendo criticada na academia, principalmente porque menospreza a existência de ações desenvolvidas com iniciativas de outros atores.

O empreendedorismo começou, então, a ser estudado a partir de outra perspectiva de análise: a ação empreendedora (Gomes, 2010). Ao centrar as atenções na ação em si e não no sujeito empreendedor, Lima (2010) considera o ato de empreender mais relevante do que quem o pratica. Nesse mesmo sentido, nas concepções de Alford e Hughes (2008), uma ação empreendedora pública é aquela que consegue criar valor público, contando, para tanto, com o esforço coletivo de indivíduos ou de organizações, na busca por melhores resultados sociais.

Com base nos preceitos da ação empreendedora, este estudo se interessou em investigar as ações desenvolvidas no esporte, tendo em vista seu reconhecimento como um mecanismo de bem-estar social e de democratização, devido às dimensões sociais 
que abrange (Eiras, Silva, Souza, \& Vendruscolo, 2010). O município de Lavras/MG foi escolhido, por sua vez, em razão da vivência histórica na área esportiva, experimentada outrora pela cidade, que viu despontar atletas de sucesso, mas que não alcança mais o mesmo reconhecimento; e também pelos investimentos do município nessa pasta, nos últimos anos, mesmo sem políticas públicas significativas relacionadas ao esporte.

Nesse sentido, surgiu a seguinte indagação: como as ações no esporte são desenvolvidas em Lavras/MG? Diante disso, objetivou-se, especificamente, conhecer o contexto dessas ações, para compreender como elas ocorrem e se podem ou não ser caracterizadas como empreendedoras.

Espera-se, a partir dos resultados desta pesquisa, oferecer contribuições teóricas, metodológicas e práticas ao campo estudado. Em termos teóricos, a discussão sobre a ação empreendedora e suas especificidades, no contexto público, poderão auxiliar no entendimento, na definição e na disseminação do conceito, que ainda carece de consenso. Em termos metodológicos, a utilização da pesquisa-ação demonstra a possibilidade de aplicação de uma metodologia prática para os estudos de empreendedorismo. Quanto aos aspectos práticos, o estudo mostra que avaliar o empreendedorismo, por meio das ações empreendedoras, é a maneira mais efetiva de se compreender a essência de um feito empreendedor. Para tanto, o framework ora proposto será um grande aliado nesse sentido.

\section{REFERENCIAL TEÓRICO}

\subsection{POLÍTICAS PÚBLICAS E O ESPORTE}

Segundo Rodrigues (2010, p. 28), conceituar política pública não é uma tarefa simples, pois não se pode compreendê-la apenas como uma "mera decisão". Essa consideração corrobora a definição de Rua e Aguiar (2007, p. 1), sobre a política pública ser um conjunto de decisões para alocar os recursos públicos, que "[...] geralmente envolve mais do que uma decisão e requer diversas ações selecionadas estrategicamente para implementar as decisões tomadas".

Já Hofling (2001), em contrapartida, aborda a política pública como o "Estado em ação", ou seja, a concretização ou a materialização das ações dos governantes, por intermédio da implantação de projetos de governo, e de programas e ações voltadas à sociedade.

Entretanto, é importante ressaltar que, diferentemente das organizações privadas, na administração pública, qualquer decisão só pode ser realizada de acordo com o que está previsto em lei, pois, "na administração pública não há liberdade nem vontade 
pessoal. Enquanto na administração particular é lícito fazer tudo que a lei não proíbe, na administração pública só é permitido fazer o que a lei autoriza" (Meirelles \& Paixão, 2003 , p. 86). Em outras palavras, para praticar qualquer ato, o gestor deve atuar por meio de políticas públicas, as quais, segundo Souza (2006, p. 26), após serem "desenhadas e formuladas, desdobram-se em planos, programas e projetos [...]".

Tal desdobramento está contido no art. 165, da Constituição Federal Brasileira (1988), que estabelece a criação de leis, pelo poder executivo, para estabelecer o plano plurianual, as diretrizes orçamentárias e os orçamentos anuais, explicitando objetivos e metas responsáveis por fixar as despesas públicas. Assim, uma política pública é aquela que está prevista nas peças orçamentárias, conhecidas como: Plano Plurianual (PPA), Lei de Diretrizes Orçamentárias (LDO), Lei Orçamentária Anual (LOA) e Quadro de Detalhamento de Despesas (QDD).

Nesse sentido, os recursos públicos devem ser distribuídos no orçamento, para garantir os direitos fundamentais da sociedade, como: acesso à educação e à saúde, assistência social (Nogueira, 2001), lazer e esporte. Para Tubino (2010), a área esportiva merece a atenção das políticas públicas, porque não se trata apenas de um direito da sociedade - previsto e assegurado pela Constituição da República (1988) (“Art. 217. É dever do Estado fomentar práticas desportivas formais e não formais, como direito de cada um...") -, mas de um mecanismo de bem-estar social, de democratização e de relevância sociocultural, que abrange outras dimensões sociais, além da qualidade na saúde, configurando-se, dessa maneira, como um grande compromisso para com a formação cidadã.

Dito em outros termos, o esporte transcende os ambientes culturais e sociais, estando presente em diversos contextos e em todo o mundo, como instrumento agregador de diferenças sociais, como a diversidade de classes, de religião e de gêneros (Ratten, 2011; Bickel, Marques, Santos, 2012). Nas palavras de Brito (2012, p. 7),

[...] o esporte representa um grande elemento de identidade nacional e importante meio de inclusão social, sendo comprovadamente uma ferramenta que, se utilizada adequadamente, auxilia a construção e aquisição de valores éticos e morais, permitindo ainda o desenvolvimento intelectual, facilitando o aprendizado e o convívio social de crianças e jovens, além da melhoria de seu bem-estar físico e promoção da saúde.

Nesses termos, o esporte pode ser uma importante ferramenta para a gestão pública, pois demonstra o compromisso e a responsabilidade social, abrindo possibilidades para a construção de valores sociais e de uma sociedade mais igualitária (Silva, Terra, \& Votre, 2006). 
Além disso, por apresentar tamanha relevância e impacto social, o esporte é uma área propensa ao desenvolvimento do empreendedorismo, tendo em vista que a inovação e a mudança são elementos-chave de seu contexto (Ratten, 2011), que, se associados a algumas finalidades, como bem-estar físico, inclusão e convívio social, tornam-se também propícios ao desenvolvimento de ações empreendedoras.

\subsection{O EMPREENDEDORISMO, AS AÇÕES EMPREENDEDORAS E SEUS ATORES}

O empreendedorismo é um fenômeno mundial, que impulsiona a economia e promove o desenvolvimento social de um país, ao trazer inovações, fomentar as atividades produtivas, e permitir a atualização de processos que precisam ser melhorados (Cunha, Silva, \& Yamaguchi, 2011).

Em sua origem, o termo foi utilizado para definir a ação "daquele que assume riscos e começa algo novo" (Zen \& Fracasso, 2008), estando, portanto, intrinsicamente ligado ao ato de um indivíduo. Como o empreendedor é um ser social e vive das relações que estabelece, uma visão essencialmente pautada nas suas competências e no seu perfil passou, a princípio, a ser propagada (Paiva Júnior, 2004). Essa perspectiva, contudo, começa a ser questionada por autores, como: Zen e Fracasso (2008), Paiva Júnior e Mello (2009), Gomes (2010), e Gomes, Lima e Cappelle (2013), para os quais, o resultado de um ato é mais relevante do que quem o pratica.

Surge, então, outra lente de estudos do empreendedorismo - a ação empreendedora, preocupada com a ação, propriamente dita, e com os seus efeitos no meio onde ela é produzida (Gomes et al., 2013). Diferenciada do empreendedorismo clássico, por apresentar uma abordagem focada na ação, independentemente de quem a idealiza ou de quem a coloca em prática, ela pode ser realizada pelo empreendedor, assim como pelos demais integrantes da organização.

Embora a ação empreendedora seja distinta, no contexto público, a discussão sobre o assunto ocorre de forma semelhante nas organizações privadas, diferenciandose apenas em relação à finalidade dos atos e ao ator que os pratica. O conceito de empreendedorismo passou a se tornar atrativo para o setor público, a partir das reformas neoliberais, iniciadas com Margaret Thatcher, na Inglaterra, e com Ronald Reagan, nos Estados Unidos. Elas culminaram na New Public Management (Kim, 2010) - a incorporação de métodos gerenciais das organizações privadas para a gestão pública, como, por exemplo, a ideia de governo empreendedor. No Brasil, essa nova administração ficou conhecida como "Administração Pública Gerencial”, passando a ser 
utilizada a partir de 1995, quando houve a reforma do aparelho estatal brasileiro (Bresser-Pereira, 2010).

O empreendedorismo público pode ser compreendido como uma ação ou mais ações capazes de melhorar a alocação dos recursos, com fins de promover benefícios à população (Kim, 2010). Dessa maneira, essa vertente deixa de lado a questão estritamente econômica, passando a definir o empreendedorismo em termos de tomada de decisão, de inovação e de proatividade do gestor (Diefenbach, 2011), o que o mantém atrelado à prática de um indivíduo, isto é, ligado à imagem inovadora do governante e de seu governo (Valadares et al., 2012).

A ação empreendedora, no contexto público, preocupa-se com as mudanças sociais (Silva, Valadares, \& Andrade, 2016), não sendo, com isso, um ato do "empreendedor público", mas do esforço coletivo, na busca por melhores resultados sociais (Zen \& Fracasso, 2008). Assim, ela pode ser realizada por vários atores: o empreendedor público, os servidores ou mesmo a sociedade civil e a iniciativa privada.

Para compreender melhor o papel desempenhado por esses atores na gestão pública, alguns pesquisadores preferem conceituá-los, como o fazem: Beyers e Kerremans (2004), para os quais, todos os que atuam na gestão pública são essencialmente "burocratas"; ou Lotta (2012), que denomina os servidores de linha de frente, como professores, médicos e assistentes sociais, de "burocratas de nível de rua", devido à sua responsabilidade em fazer a política pública alcançar a sociedade. Pires (2012) por sua vez chama de "Burocratas de Nível Médio" ou de "Médio Escalão" aqueles ocupam cargos assessorando os gestores nas decisões políticas e na formulação de políticas públicas e Borges e Cappelle (2018) que a partir dos trabalhos anteriores cunharam o termo "Burocratas do Colarinho Branco", para caracterizar aqueles que possuem discricionariedade para tomar decisões nas organizações públicas, ou seja, Prefeitos, Secretários Municipais, Governadores, Secretários de Estado, Presidente da República e Ministros, por exemplo (Figuras 1 e 2). 


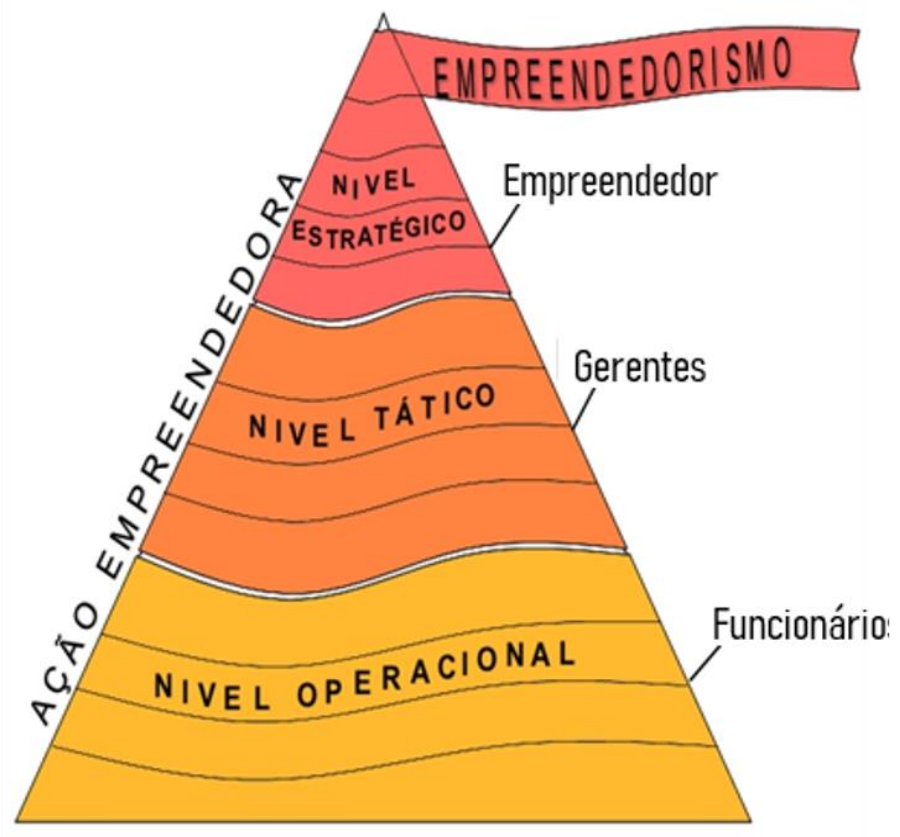

Figura 1. Empreendedorismo x Ação Empreendedora, no Setor Privado Fonte: Elaborada pelos autores (2018), a partir de Sobral e Peci (2013).

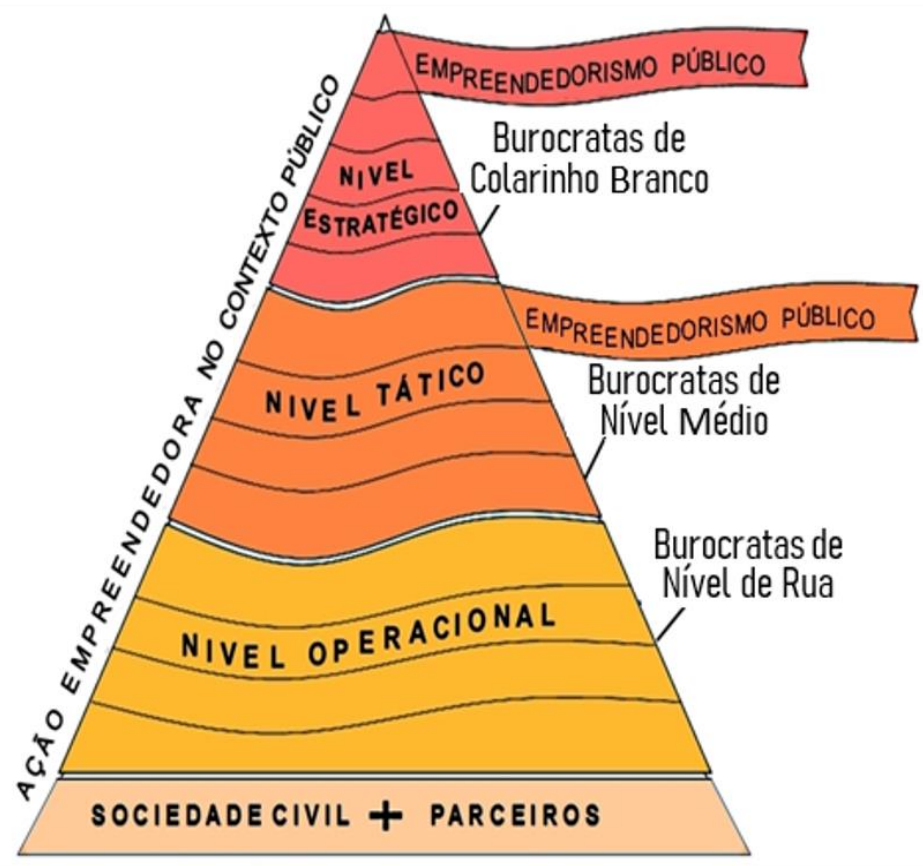

Figura 2. Empreendedorismo Público x Ação Empreendedora, no Contexto Público Fonte: Elaborada pelos autores (2018), a partir de Sobral e Peci (2013).

Fazendo alusão à pirâmide organizacional (Sobral \& Peci, 2013), que apresenta os três níveis organizacionais, percebe-se que o empreendedorismo clássico, praticado nas organizações do setor privado, é resultado apenas da iniciativa do empreendedor, ou seja, das decisões daqueles que ocupam o nível estratégico, indo ao encontro dos preceitos de Cunha et al. (2011). Já a ação empreendedora, de acordo com os conceitos definidos por Gomes (2010), é uma prática que pode ser iniciada por qualquer 
indivíduo do meio organizacional: o empreendedor, os gerentes do nível tático e os funcionários do nível operacional.

O empreendedorismo público, por sua vez, é um ato praticado apenas pela cúpula organizacional ("burocratas do colarinho branco" e "burocratas de nível médio"). Já uma ação empreendedora pode ser iniciativa de vários atores: a sociedade civil e outros parceiros, como a iniciativa privada, por exemplo, os "burocratas de nível de rua", "nível médio" ou mesmo os próprios "burocratas de colarinho branco". É importante destacar que essas ações podem se tornar políticas públicas, se forem planejadas nas peças orçamentárias; entretanto, uma política pública, por si só, não pode ser considerada uma ação empreendedora.

\subsection{UM FRAMEWORK PARA AÇÕES EMPREENDEDORAS}

Uma ação empreendedora surge, muitas vezes, a partir de um acontecimento, compreendido por um ou mais atores como um problema (Monllor \& Murphy, 2017). Aqueles que se identificam com essas situações, percebem a ação empreendedora como uma possibilidade de criar valor econômico e/ou social e, assim, resolver a questão (Viswanathan, Echambadi, Venugopal, \& Sridharan 2014). Sendo assim, no contexto público, as ações empreendedoras não são identificadas por grandes inovações ou empreendimentos, mas pelo significado social que proporcionam (Silva et al., 2016). O valor público criado (Alford \& Hughes, 2008), nas palavras de Sousa, Paiva Júnior e Lira (2010, p. 341), não se deve ao "fato de algo ser oferecido pelo setor público, mas por se tratar de um valor produzido por ações coletivizadas e consumido coletivamente pelo cidadão".

Por compartilhar objetivos, as ações empreendedoras contam com a presença de vários atores, dando voz, inclusive, àqueles que nem sempre tiveram a oportunidade de participar das decisões políticas, e que formam o "exército de esquecidos" de Gomes (2010, p. 103). Nesse esforço coletivo (Zen \& Fracasso, 2008), almeja-se também compreender as interações que se estabelecem entre os atores, no processo da ação (Spedale \& Watson, 2014), que são dotadas de significados (Paiva Júnior, 2004), em razão dos resultados positivos, que causam na sociedade, e pela progressão pessoal e social dos envolvidos (Silva et al., 2016). Outra característica é a existência de princípios e de valores éticos na ação, tendo em vista que a presença desses fatores traz credibilidade e confiança, favorecendo a construção de parcerias e de alianças entre setor público, setor privado e sociedade civil como um todo (Sousa et al., 2010). 
Além disso, uma das características mais relevantes da ação empreendedora, no contexto público, é o compromisso com a mudança (Gomes et al., 2013), provocando a transformação da realidade existente em uma nova realidade. De acordo com Nascimento (2018), avaliar o empreendedorismo, no contexto público, por meio das ações empreendedoras, é a maneira mais efetiva para compreender a essência de um feito empreendedor. Por isso, conhecer os aspectos que caracterizam uma ação empreendedora é extremamente necessário e igualmente importante para definir uma ação dessa forma (Figura 3).

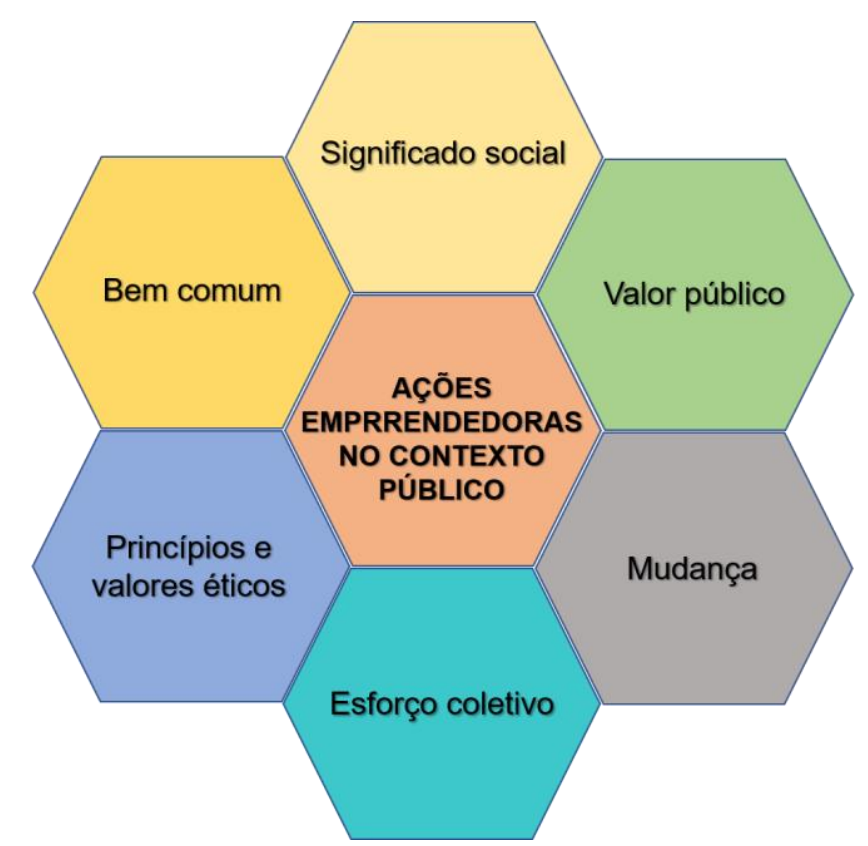

Figura 3. Framework das ações empreendedoras no contexto público

Fonte: Elaborada pelos autores (2018), a partir dos autores citados no subcapítulo.

A partir dos autores citados anteriormente, foi elaborado um framework para orientar os pesquisadores a atribuir o caráter empreendedor a uma ação. Dessa maneira, as ações empreendedoras, no contexto público, podem ser conceituadas como aquelas que juntam esforços coletivos, e observam os princípios e os valores éticos, com o objetivo de promover o bem da coletividade, resultando na criação de valores, sem necessariamente ter se originado do próprio poder público. Assim, as ações empreendedoras são comprometidas com a mudança, possuem significado social, e transformam a realidade do contexto e dos atores onde estão inseridas.

\section{PROCEDIMENTOS METODOLÓGICOS}

O rigor metodológico é um dos pontos mais relevantes para assegurar a validade de uma pesquisa científica, estando intrinsicamente associado ao posicionamento 
ontológico e epistêmico do pesquisador (Dresch, Lacerda \& Miguel, 2015). Assim, considerando os objetivos de pesquisa, a partir da matriz das ciências sociais, de Burrell e Morgan (1979), este estudo (Figura 4) foi orientado por um posicionamento epistemológico interpretativista, pois buscou compreender a realidade por meio das interações sociais, dos atores envolvidos, do significado das ações e do conhecimento do senso comum (Berger \& Luckmann, 2010). Com base na abordagem subjetivista, foi adotada também uma metodologia qualitativa, conhecida por pesquisa-ação. A escolha se deu em virtude da sua possibilidade de intervir no meio - característica marcante, que a difere de outras metodologias qualitativas (Thiollent, 2003).
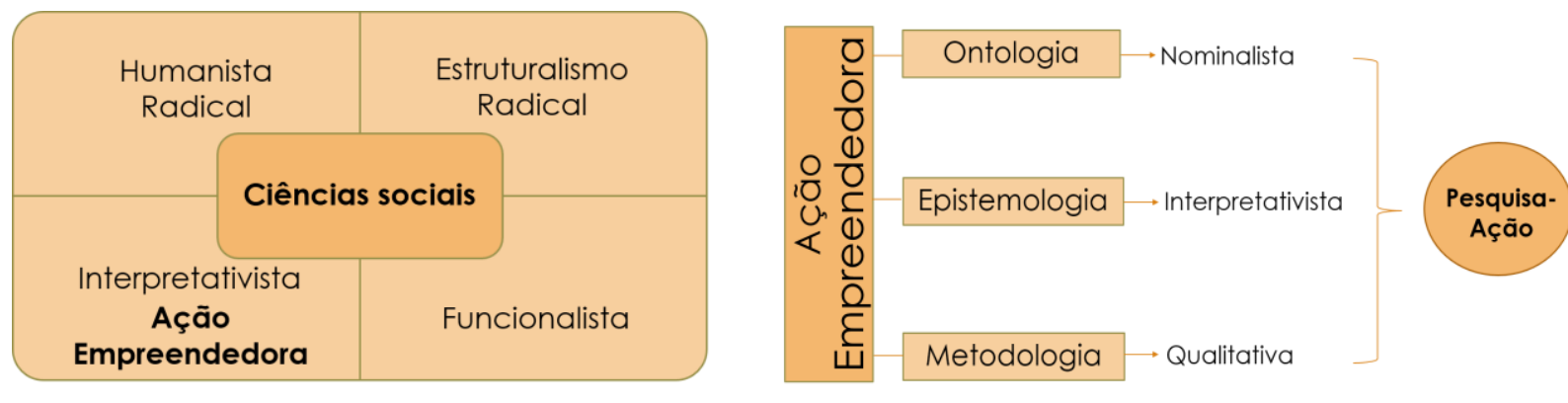

Figura 4. Posicionamento da pesquisa

Fonte: Elaborada pelos autores (2018), a partir da matriz de Burrell e Morgan (1979).

Escolheu-se: (1) o esporte como área de investigação, porque a promoção esportiva é uma obrigação prevista em lei, e o esporte apresenta um contexto propenso a ações, em face do seu alcance social; (2) o Município de Lavras, em Minas Gerais, como campo de estudo, devido ao cenário histórico já vivenciado pela cidade, na área esportiva, e pelos investimentos municipais, feitos nos últimos anos, nessa pasta; e (3) o projeto "Arremesso para um Novo Horizonte", como fenômeno de investigação, por ele apresentar características de uma ação empreendedora.

Na primeira, das seis fases de desenvolvimento da pesquisa, houve o seu registro na Pró-Reitoria de Pesquisa da Universidade, e a sua submissão ao Comitê de Ética em Pesquisa com Seres Humanos da Universidade Federal de Lavras (COEP/UFLA), por meio da Plataforma Brasil, a fim de cumprir os requisitos legais e éticos, obrigatórios em investigações científicas. Foi solicitada, então, à Prefeitura Municipal de Lavras, a autorização para que o estudo pudesse ser realizado.

$\mathrm{Na}$ segunda fase, que ocorreu no segundo semestre de 2017, iniciou-se a pesquisa empírica, com o levantamento das políticas públicas desenvolvidas pela Prefeitura. Nesse momento, a pesquisa documental foi utilizada como instrumento de coleta de dados, por meio de: (a) buscas no site oficial do município; (b) análise das 
peças orçamentárias PPA, LDO e LOA, concretizadas no período de 2014 a 2017; do PPA, planejado para ser executado no interstício de 2018 a 2021; e das LDO e LOA, organizadas em 2017, para efetivação em 2018. Além disso, houve uma primeira entrevista com o Secretário Municipal de Esportes do Município, para respaldar a pesquisa documental e verificar a existência de outras ações, que não estavam previstas nos instrumentos de gestão. Assim, oito projetos (futsal masculino e feminino, basquete, handebol, voleibol, e escolinhas de capoeira, de karatê e de taekwondo) foram listados e visitados, com o objetivo de identificar, na prática, se estavam alinhados ao objeto de pesquisa. Dentre eles, uma ação desenvolvida em um dos bairros se destacou, devido às características próximas de uma ação empreendedora, sendo selecionada como objeto de investigação.

A terceira fase (primeiro semestre de 2018) marcou a entrada em campo da pesquisadora, que fora apresentada como auxiliar técnica, para participar dos treinos, com vestimenta específica à prática de esportes; envolver-se nos jogos de basquete; e promover a interação com os demais atores. Os dados, nessa fase, foram coletados por meio da observação participante, e registrados em diários de campo, para descrever detalhadamente a ação, seus participantes, a relação entre eles, e subsidiar a inferência das entrevistas. As informações, portanto, ficaram diluídas ao longo dos resultados.

Durante a pesquisa de campo, também foram encontrados e analisados documentos importantes, como redações feitas na escola por alunas e registros do projeto. Paralelamente à participação direta no campo, foram realizadas entrevistas com: o Secretário de Esportes do Município (entrevistado pela segunda vez); o idealizador da ação; o patrocinador; uma assistente social do bairro; e um jornalista de um dos jornais locais, que produziu diversas matérias sobre o esporte em Lavras, evidenciando a posição do município no contexto esportivo. Realizadas a partir de um roteiro aberto e não estruturado, e gravadas, após a assinatura do Termo de Consentimento Livre e Esclarecido (TCLE), as entrevistas permitiram associar os discursos e as percepções de campo. Para preservar a identidade dos participantes, eles foram identificados pelo papel que desempenham e pelas atividades que exercem. O perfil dos entrevistados e a relevância de cada um para o estudo estão apresentados a seguir (Figura 5). 


\begin{tabular}{|c|c|c|c|c|}
\hline Entrevistado & Gênero & $\begin{array}{c}\text { Código de } \\
\text { Identificação }\end{array}$ & Função & Relevância para a Pesquisa \\
\hline $\begin{array}{l}\text { Secretário de } \\
\text { Esportes, } \\
\text { Lazer, } \\
\text { Turismo e } \\
\text { Cultura }\end{array}$ & Masculino & $\begin{array}{l}\text { Secretário de } \\
\text { Esportes }\end{array}$ & $\begin{array}{l}\text { Responsável pelas } \\
\text { políticas públicas } \\
\text { desenvolvidas no } \\
\text { esporte de Lavras. }\end{array}$ & $\begin{array}{l}\text { Contribuiu para o } \\
\text { levantamento de políticas, } \\
\text { projetos e ações, } \\
\text { desenvolvidas no município, } \\
\text { no âmbito do esporte. }\end{array}$ \\
\hline $\begin{array}{l}\text { Idealizador da } \\
\text { Ação }\end{array}$ & Masculino & Idealizador & $\begin{array}{l}\text { Idealizador da ação } \\
\text { estudada. Atualmente, é } \\
\text { servidor público e } \\
\text { professor responsável } \\
\text { pelos treinos. }\end{array}$ & $\begin{array}{l}\text { Foi fundamental para expor a } \\
\text { ação estudada, apresentando } \\
\text { objetivos, pretensões e a } \\
\text { história do projeto. }\end{array}$ \\
\hline $\begin{array}{l}\text { Patrocinador } \\
\text { da Ação }\end{array}$ & Masculino & Patrocinador & $\begin{array}{l}\text { Auxilia o projeto, } \\
\text { patrocinando lanches, } \\
\text { uniformes e viagens } \\
\text { para jogos externos. }\end{array}$ & $\begin{array}{l}\text { Foi relevante para a } \\
\text { compreensão do projeto, } \\
\text { como ação social coletiva. }\end{array}$ \\
\hline $\begin{array}{l}\text { Assistente } \\
\text { Social }\end{array}$ & Feminino & $\begin{array}{l}\text { Assistente } \\
\text { Social }\end{array}$ & $\begin{array}{l}\text { Acompanha os jovens e } \\
\text { seus familiares na ação. }\end{array}$ & $\begin{array}{l}\text { Contribuiu para verificar o que } \\
\text { a ação estudada representa } \\
\text { na vida das pessoas e da } \\
\text { comunidade que dela } \\
\text { participam. }\end{array}$ \\
\hline $\begin{array}{l}\text { Jornalista } \\
\text { Editor-Chefe }\end{array}$ & Masculino & Jornalista & $\begin{array}{l}\text { É servidor público na } \\
\text { Diretoria de } \\
\text { Comunicação e Editor- } \\
\text { Chefe de um jornal local. }\end{array}$ & $\begin{array}{l}\text { Contribuiu para situar o } \\
\text { município no cenário } \\
\text { esportivo, compreendendo as } \\
\text { suas relações com o esporte. }\end{array}$ \\
\hline
\end{tabular}

Figura 5. Perfil, identificação e relevância dos entrevistados Fonte: Elaborada pelos autores (2018).

$\mathrm{Na}$ quarta fase da pesquisa (segundo semestre de 2018), aconteceu a análise e a interpretação dos dados obtidos, que foram tratados conforme os seguintes critérios: (a) transcrição integral das entrevistas e posterior, estudadas por meio da técnica de análise de conteúdo, de Bardin (2011); (b) sistematização de todo o material coletado, a partir da retomada dos objetivos iniciais propostos; (c) identificação das categorias prévias, a partir dos objetivos; (d) desmembramento e reagrupamento dos dados, de acordo com as categorias prévias; (e) agrupamento dos dados que não se encaixaram nas categorias criadas, em categorias emergentes; e (f) análise temática, a partir da relevância dos temas, com o intuito de identificar os núcleos de sentido.

É importante ressaltar que a categorização seguiu a grade mista, ou seja, categorias prévias já definidas, a partir dos objetivos de estudo; e categorias emergentes, que surgiram dos dados coletados em campo, conforme apresentado a seguir (Figura 6). 


\section{CATHEORAIS PRÉVIAS E EMERGENUES}

Categoria 1: Lavras e seu destaque no cenário desportivo (categoria emergente)

Categoria 2: Políticas públicas desenvolvidas no esporte de Lavras (categoria prévia)

Categoria 3: O projeto "Arremesso para um Novo Horizonte": uma ação para o esporte em Lavras (categoria emergente)

Categoria 4: A ação estudada no esporte pode ser considerada empreendedora? (categoria prévia)

Categoria 5: Intervenções, mudanças e possíveis articulações entre políticas públicas e ações empreendedoras (categoria prévia)

Figura 6. Categorias utilizadas na análise temática Fonte: Elaborada pelos autores (2018).

À medida que a pesquisa de campo progredia, foram encontrados alguns dados, não previstos pelo estudo e tampouco determinados nos objetivos específicos, mas que se mostraram relevantes à compreensão do fenômeno investigado. O contexto esportivo de Lavras e o projeto "Arremesso para um Novo Horizonte" exemplificam esses dados, transformados em locus investigativo, e para os quais foram criadas duas novas categorias, chamadas de emergentes, pela técnica de Bardin (2011). Posteriormente, as categorias deram origem aos títulos, utilizados nos resultados e nas discussões.

$\mathrm{Na}$ quinta fase, realizada ainda em 2018, foi feito um brainstorming com todos os participantes, para discutir as propostas de intervenção. E por fim, a sexta fase, em 2019, houve o retorno ao campo, para avaliar as mudanças proporcionadas pelas intervenções.

\section{RESULTADOS E DISCUSSÕES}

\subsection{LAVRAS E SEU DESTAQUE NO CENÁRIO DESPORTIVO}

Segundo dados do Instituto Brasileiro de Geografia e Estatística (IBGE, 2010), Lavras - município localizado na região conhecida como "Campo das Vertentes", no sul do estado de Minas Gerais - possui uma população estimada de 92.200 habitantes, e um Índice de Desenvolvimento Humano (IDH) significativo, de 0,782. Aproximadamente $41 \%$ de sua população, de acordo com o Ministério do Desenvolvimento Social e Combate à Fome (2009), é composta por jovens de até 18 anos, em fase de formação e de desenvolvimento pessoal, social e profissional. Esse cenário é propício ao desenvolvimento de práticas esportivas, pois, nessa faixa etária, o esporte não auxilia apenas à aquisição de aptidão física, mas favorece a formação do indivíduo, bem como o seu convívio em sociedade (Bernardes, Yamaji, \& Guedes, 2015). 
Com um histórico significativo no cenário esportivo (Silva, 2017), como ressalta o jornalista local, entrevistado por esta pesquisa, o município foi sede de times importantes na disputa de campeonatos da primeira divisão, como o Fabril Esporte Clube, com sucesso nos anos 80; e formou atletas que vestiram a camisa da seleção brasileira, como: (a) Ana Paula Rodrigues (voleibol), que disputou olimpíadas e o Grand Prix; (b) Ricardo Rogério de Brito, o Alemão (futebol), que jogou no Atlético de Madrid, no São Paulo e no Botafogo, sendo também treinador do América Mineiro; (c) Cláudio Roberto da Silva, o Caçapa (futebol), que jogou no Atlético Mineiro e no Lyon da França; (d) Admilson Bosco Chitarra (atletismo); (e) e Alfredo Scheid Lopes (atletismo).

Além disso, o município conta com a presença de duas universidades, com curso de educação física, que dispõe de quadras, ginásios, campos de futebol, pista de corrida e academias ao ar livre para a prática de esporte; e, conforme análise das peças orçamentárias municipais (PPA, LDO, LOA e QDD), nos últimos cinco anos, investiu cerca de cinco milhões de reais em infraestrutura e em materiais esportivos.

Nesse sentido, é importante salientar que os itens supracitados não fazem com que o esporte aconteça em Lavras, mas a presença desses recursos (conhecimento, infraestrutura e investimentos financeiros) gera a expectativa de existência de muitas ações esportivas.

Lavras, portanto, por essa breve descrição, com fins de contextualização (não de levantamento histórico) e de justificativa para a escolha do campo investigativo, apresenta-se como um locus de estudo interessante para o desenvolvimento de ações empreendedoras no esporte.

\subsection{POLÍTICAS PÚBLICAS DESENVOLVIDAS NO ESPORTE DE LAVRAS}

O termo "política pública" é utilizado na sociedade para definir, de forma ampla, as atividades para as quais os gestores públicos destinam os recursos financeiros oriundos da arrecadação, apontando suas finalidades, objetivos e demonstrando o cumprimento das obrigações do poder público. Entre essas ações, é previsto, no caput do art. 217 da Constituição Federal Brasileira (1988), o fomento das práticas desportivas.

Diante disso, na segunda fase da pesquisa, ao ser indagado sobre quais as políticas desenvolvidas no município, o Secretário de Esportes respondeu: "Com iniciativa do Município nós temos projetos de futsal masculino, futsal feminino, basquete, handebol e voleibol. Eles são distribuídos nas escolas... Temos também as escolinhas de capoeira, de karatê, de taekwondo". No entanto, foi verificado, durante a análise do PPA, da LDO 
e da LOA do município, que nenhum desses projetos estava previsto, de forma específica, no orçamento. Quanto a isso, ele respondeu:

"Os projetos não estão no QDD como uma ação específica né, mas nós utilizamos outras ações como a "manutenção das atividades da Secretaria", por exemplo, que tem contratação de pessoas, material de consumo pra executar o projeto. $O$ certo era até ter tudo isso no orçamento, mas esse é o primeiro ano da gestão e muita coisa a gente vai melhorando". (Secretário de Esportes)

Sendo assim, as várias atividades esportivas, realizadas em Lavras, não são consideradas políticas públicas, por não terem sido previstas, conforme instrumentos regulatórios, no orçamento público. Para que isso ocorra, após a formulação das políticas públicas, elas devem ser transformadas em planos, em programas e em projetos (Souza, 2006) que, uma vez concebidos, devem estar previstos nas peças orçamentárias: PPA, LDO e LOA, conforme preconiza a Constituição Federal Brasileira (1988).

Foi, então, perguntado ao secretário, se ele conhecia outros projetos esportivos, realizados sob outras iniciativas, mesmo que não da Prefeitura, ao que ele respondeu:

\footnotetext{
"Tem sim uma parceria no basquete idealizada pelo [idealizador da ação]. Ele quer levar a prática de basquete nos bairros mais carentes do Município... O projeto, "Arremesso para um Novo Horizonte" é realizado em parceria com a [patrocinador da ação] e é um projeto que teve a sua base muito bem feita...". (Secretário de Esportes)
}

Uma das ações mencionadas, desenvolvida em uma região carente do município, segundo o Secretário de Esportes, foi idealizada por um professor e realizada por uma parceria entre a Prefeitura e a iniciativa privada. Esses aspectos são elencados por Sousa et al. (2010) e, por isso, tal ação foi selecionada como uma possível ação empreendedora.

\subsection{O PROJETO "ARREMESSO PARA UM NOVO HORIZONTE”: UMA AÇÃO PARA O ESPORTE EM LAVRAS}

A ação, destacada pelo Secretário de Esportes, é o projeto "Arremesso para um Novo Horizonte", estudado na terceira fase desta pesquisa, que começou da seguinte maneira:

"Eu estava na Secretaria de Esportes e não tinha muito espaço pra realizar os meus sonhos lá, aí conversei com [ex-prefeita] e pedi pra ir pro Novo Horizonte. Uma das razões foi que eu já sabia dos problemas do bairro né, que era muito discriminado e que tinha uma fama muito ruim. Aí, pensando em oferecer uma opção de lazer pra comunidade e o que eu gosto de fazer é o basquete pensei em montar uma escolinha sem pretensões nenhuma de competição. No começo eles iam descalços, as meninas umas iam de saia, chinelo [risos] de tudo quanto era jeito. Eu tinha as bolas, uma quadra péssima e os meninos totalmente indisciplinados". (Idealizador) 
De acordo com o idealizador, o projeto teve início em 2007, em um bairro escolhido por conta da fragilidade vivenciada pela comunidade local. A falta de estrutura física e o material esportivo escasso foram as primeiras dificuldades enfrentadas para o desenvolvimento da ação.

Para melhor compreender essa ação, foi solicitado a uma assistente social do bairro que discorresse sobre o assunto. Segundo ela,

"O projeto já está lá há dez anos e vem fazendo um trabalho bacana com as crianças que residem naquele bairro... É um território assim que tem uma vulnerabilidade grande, né. O projeto vem pra atender essas crianças na área social, de saúde e tudo através do esporte, é através daquilo que eles gostam de fazer que nós vamos conseguir resgatar e dar mais oportunidade a essas crianças". (Assistente Social)

A ação é percebida pela assistente social como uma possibilidade de modificar a situação vulnerável da comunidade local. Boszczowski e Teixeira (2012), ao definirem ação empreendedora, revelam que ela está engajada em proporcionar uma situação de maior bem-estar social. Segundo os relatos, o projeto atende, atualmente, cerca de 150 crianças e adolescentes, de ambos os sexos, na faixa etária entre 8 a 14 anos. Seu objetivo, nas palavras do idealizador, é: "ensinar pelo basquete lições para toda a vida". É perceptível, nas falas, que o projeto envolve várias pessoas com o mesmo propósito:

"Acima de tudo a gente tem que preparar os jovens para a vida. Provavelmente, alguns deles lá no projeto não vão querer ser atletas profissionais do basquete, mas então que sejam pessoas corretas, bons profissionais e por isso é importante incluir a cultura da educação...". (Secretário de Esportes)

"O esporte, essa energia do esporte, isso sozinho não é o suficiente... Por isso, é preciso ensinar também valores". (Patrocinador)

Um dos aspectos mais relevantes em uma ação é o resultado gerado no espaço onde ela está sendo realizada. Nesse sentido, é possível notar que as pessoas envolvidas nessa ação não estão focadas em encontrar "grandes talentos do esporte", mas em formar cidadãos conscientes, que tenham possibilidades de fazer escolhas pessoais e profissionais, o que vai ao encontro da progressão pessoal e social dos envolvidos, enfatizada por Silva et al. (2016).

Além disso, para Sousa et al. (2010), a presença de princípios e valores éticos na ação tem grande relevância, não só porque transmite credibilidade para conquistar o apoio de outros atores, como também imprime confiança para a comunidade local e para os envolvidos. Observa-se que essa ação não é descrita apenas como um projeto de esporte, havendo outros pilares, em sua construção, que permitem descrevê-la como um conjunto de atos de várias pessoas, integradas em uma cadeia e preocupadas com o bem-estar social das pessoas: 
"Há uma combinação boa que funcionou esses anos de... prefeitura, iniciativa privada, da própria comunidade e de um técnico muito motivado e muito competente". (Patrocinador)

"No projeto nós contamos com o apoio da [patrocinador da ação], da prefeitura e das pessoas que veem conhecer o projeto e ficam encantadas né". (Idealizador)

"... nós temos um suporte bem direcionado do setor público médico que já existe pra fazer um acompanhamento maior de todo mundo que tá no projeto até mesmo como uma forma de acompanhá-los fisicamente". (Patrocinador)

"É um projeto que teve a sorte de contar com o apoio de muita gente". (Secretário de Esportes)

A reunião de vários atos conjuntos, como os citados nos relatos, entre organização pública, organização privada e comunidade local, em busca do mesmo objetivo, é vista por Souto (2006) como uma forma de se chegar a bons resultados sociais.

\subsection{A AÇÃO ESTUDADA NO ESPORTE PODE SER CONSIDERADA EMPREENDEDORA?}

Para uma ação, no contexto público, ser considerada empreendedora, ela precisa apresentar algumas características específicas, entre elas, estão: conter princípios e valores éticos (Sousa et al., 2010); ser desenvolvida com esforços coletivos (Zen \& Fracasso, 2008); precisa criar valor público (Alford \& Hughes, 2008); ser dotada de significados (Paiva Júnior, 2004); e provocar mudanças (Silva et al., 2016).

A partir do framework apresentado, procedeu-se, então, com a análise da ação, na quarta fase da pesquisa. Em termos de esforços coletivos, em um de seus relatos, o idealizador expõe como as relações foram construídas:

"Tiveram uns jogos aqui e o presidente da FEEMG [Federação de Esportes Estudantis de Minas Gerais] resolveu ir lá pra ver como era. A hora que ele viu os meninos ele falou assim: 'Você só tem esse material?' Falei: 'é!' 'Alguém te ajuda?' Falei: 'não!'. Aí me chega um furgão com bola de basquete, cone, aro, colchonete... Aí, ele fala: 'São muito pobres! [choro]. Você dá lanche?' Falei: 'não!' Ele falou: 'faz o orçamento, eu vou mandar o dinheiro.' Aí procurei o [patrocinador da ação] que falou: 'faço o iogurte e a muçarela a preço de custo.' Aí fui na padaria, expliquei... 'faço o pão a preço de custo' [rsrs]. Aí o presidente da FEEMG mandava o dinheiro e depois de um tempo o [patrocinador da ação] falou: 'não cobro mais!'” (Idealizador)

É interessante lembrar que a ação começou com a pretensão de oferecer uma atividade de lazer para os jovens; entretanto, a credibilidade do projeto foi fazendo com que algumas instituições e a iniciativa privada se interessassem pela ação, assim como pessoas da sociedade civil e o poder público:

“Encontrei um ex-atleta e ele falou: 'pra que é esse tanto de pão?' [risadas]. Falei: 'pra um projeto de basquete.' Ele falou: 'eu pago!' Aí liguei pro [Presidente da FEEMG] e falei que não precisava mais e ele falou: 'mas material esportivo eu mando!' $E$ aí foi melhorando... [choro]. A Prefeitura nos dava a quadra pra treinar e o transporte". (Idealizador) 
Os esforços conjuntos, em uma ação empreendedora, independem de quem atua nela, pois o que é relevante é a criação do valor público, isto é, ser realizada com empenhos conjugados e utilizada de forma coletiva pelas pessoas, provocando, assim, possibilidades de mudança de uma realidade vulnerável. Quanto a essa realidade, a assistente social destaca:

"Visitando as famílias, a gente percebe uma carência de um a tudo. Então, esse projeto, né, vem provocar um processo de mudança na vida daquelas crianças. Nas minhas visitas, eu vi casos de famílias que tem arroz, mas não tem feijão; na outra tem feijão, mas não tem arroz... carne e verdura só de vez em quando. Então eu vejo que são casos de extrema vulnerabilidade mesmo. Em cada família que eu visitei, eu vi a dependência química instalada, se não é dependência de uma coisa, é de outra [...]". (Assistente Social)

Essa situação social também é destacada pelo idealizador:

"Muitos iam treinar porque não tinham o que comer [choro]. Uma vez entrevistaram uma das meninas: 'você gosta de basquete?' Ela falou assim: 'eu nem sabia o que que era isso. Aí, o projeto veio pra cá e eu fiquei sabendo que tinha um lanche, eu vinha por causa do lanche, eu queria comer. Olha que coisa! E aí começaram a gostar do basquete... (Idealizador)

É possível perceber que há problemas sociais sérios no bairro, e isso, de alguma forma, reflete-se na vida dos jovens, que vivenciam essa situação cotidianamente. Por isso, a assistente social enfatiza que um dos propósitos da ação é mostrar aos jovens que eles podem ter novas oportunidades para o futuro: "A ideia é fazer com que aquelas pessoas se motivem, né, pra novas perspectivas na vida, ter sonhos [...]" (Assistente Social).

Neste sentido, o vínculo de confiança proporcionado pela ação faz com que essa possibilidade de mudança se torne real.

"Algumas meninas já saíram do basquete e retornam com os filhos. Os pequenininhos deixam de ficar na rua e vão pro projeto... criou-se um elo de confiança, de amor entre o treinador, o projeto e aquelas crianças. A situação que você presenciou lá é uma sensação de segurança, de estar bem, de tá sendo assim... valorizados enquanto pessoa". (Assistente Social)

Nessa linha, a ação está associada a muitos aspectos positivos, no contexto social (Silva et al., 2016). Nas palavras de duas jovens participantes do projeto, percebe-se o que a ação representa na vida delas:

"A Sensação do Esporte: o basquete é a vida, a união e o respeito, nos exige muita dedicação para um tempo perfeito. Sonho em ser alguém na vida, vencer e ser reconhecida. Por isso luto para o meu sonho realizar e com muito êxito alcançar..." (Trecho 1: Poesia de uma participante da ação)

"Esporte é Saúde: O esporte nos une nos faz acreditar que lá no futuro alguém importante vamos virar. Acreditar, vencer, batalhar... basquete vamos jogar. Quero ser alguém na vida estudo, jogo, quero viajar, vou pra bem longe, conhecer outro lugar [...]" (Trecho 2: Poesia de uma participante da ação) 
Os trechos acima são provenientes de redações, escritas por duas participantes que estudam em escola pública, no $7^{\circ}$ ano, e têm 14 anos de idade. Observa-se que 0 projeto é dotado de sentidos, de significados e está atrelado a princípios, como o respeito, o mérito profissional, a força de vontade; ao espírito de coletividade e à busca por um futuro melhor, ao passo que também se revela como um catalisador de sonhos.

O projeto, embora tenha sido idealizado por uma pessoa, desenvolveu-se a partir do envolvimento de várias outras, inclusive, com auxílio do poder público e da iniciativa privada. Esses esforços coletivos contribuíram para que ele continuasse e pudesse superar os dez anos de existência. Isso corrobora os preceitos de Zen e Fracasso (2008) sobre a coletividade. Trata-se também de algo que é usufruído pela comunidade, criando, assim, o valor público, enfatizado por Alford e Hughes (2008).

Além disso, ficou evidente, tanto nos relatos quanto pelas observações anotadas nos diários de campo, que a ação se preocupa em passar aos jovens não somente a prática esportiva, mas valores morais e princípios éticos, construindo com isso, a percepção de cidadania, pontos relevantes destacados por Sousa et al. (2010). Essas características, unidas à credibilidade, contribuem para o êxito do projeto, tendo significados positivos na vida dos participantes e lhes possibilitando que mudanças representativas aconteçam, como propõem Silva et al. (2016).

Segundo o framework construído e desenvolvido nesta pesquisa, uma ação, para ser considerada empreendedora, precisaria agregar simultaneamente seis características essenciais: (1) ter significado social; (2) apresentar valor público; (3) ser comprometida com a mudança; (4) contar com o esforço coletivo; (5) respeitar os princípios, com valores éticos; e (6) objetivar o bem comum. Por todos esses aspectos estarem presentes, mudando a realidade social, a ação denominada de "Arremesso para um Novo Horizonte" é uma ação empreendedora, presente no contexto público de Lavras. Entretanto, é importante enfatizar que não se trata de uma política feita pela gestão pública, mas de uma ação que proporcionou valor para a sociedade em que está inserida, sem ter sido originária dessa esfera.

Também é relevante destacar a conclusão sobre o feito empreendedor da ação, possibilitada pela construção do framework, o qual permitiu a análise qualitativa de cada atributo do fenômeno investigado. A sua utilização efetiva, nas análises e na apresentação dos resultados de pesquisa, comprovam a relevância desse recurso para as investigações sobre a temática, propiciando aos pesquisadores da linha de empreendedorismo compreender melhor os fenômenos dessa área. Nesse sentido, suas categorias podem ser úteis para: avaliar o feito empreendedor de projetos sociais e 
de políticas públicas; comparar a abrangência social de um empreendimento; e auxiliar os gestores na tomada de decisão sobre a destinação de recursos públicos para o investimento, ou mesmo na realização de parcerias entre o setor público e privado. Trata-se de um método palpável, quando o propósito é a análise de ações.

\subsection{INTERVENÇÕES, MUDANÇAS E POSSÍVEIS ARTICULAÇÕES ENTRE POLÍTICAS PÚBLICAS E AÇÕES EMPREENDEDORAS}

Seguindo a metodologia proposta, foi utilizado, na quinta fase da pesquisa, um método conhecido como brainstorming. Essa atividade foi realizada de forma participativa entre os atores envolvidos: alunos, pesquisadoras, secretário, idealizador, patrocinador e assistente social, e teve como objetivo levantar, de maneira conjunta, possíveis melhorias para o projeto.

Essa equipe de pesquisa-ação recebeu treinamento, a priori, para realizar a atividade. Assim, foram propostas as seguintes intervenções: (1) constituir a ação como uma política pública, sendo prevista nas peças orçamentárias do município, mantendo o compartilhamento com os demais atores (setor privado e sociedade civil); (2) ampliação da ação para outros bairros de Lavras; (3) buscar novas parcerias, de forma que isso incentive um ciclo de ações; (4) agregar cursos profissionalizantes e outros esportes, que possam ser ministrados em conjunto com o basquete; (5) encontrar alternativas para que haja aproximação das famílias dos participantes junto à ação; (6) buscar parcerias com outros órgãos públicos, como os Governos Federal e Estadual.

O que se percebeu, em Lavras, é que o município apresenta condições históricas para promover o esporte, embora a Categoria Prévia 2 tenha indicado poucos resultados em relação ao que se esperava, quando a Categoria Emergente 1 surgiu, ou seja, as expectativas iniciais de que poderia haver muitas políticas públicas no esporte lavrense, por ser uma área prevista com tamanha relevância na legislação brasileira e, principalmente, quanto ao cenário esportivo do município. Essas expectativas, todavia, não foram alcançadas; por isso, há a necessidade de intervenção, para que a ação estudada seja configurada como uma política pública legalmente estabelecida.

Além disso, a ampliação dessa ação para outras áreas da cidade pode favorecer o surgimento de novos projetos empreendedores, estimulando o compartilhamento com outros atores sociais, por meio de parcerias, conforme enfatizou Sousa et al. (2010). Ao retomar o legado do município no esporte, com o incentivo de ações empreendedoras, como a que aqui foi investigada (articulando atividades esportivas, educação e princípios éticos), conforme se constatou nas Categorias Prévias 3 e 4, será possível 
iniciar um novo ciclo de ações, com a presença de órgãos públicos e privados. As intervenções previstas na Categoria Prévia 5 são essenciais para a efetivação da mudança, conforme citado por Gomes et al. (2013).

Para concluir o ciclo da pesquisa-ação, houve o retorno ao campo, no ano de 2019, para verificar quais intervenções foram aplicadas e quais as mudanças que elas estão gerando. Das seis intervenções propostas, apenas a primeira e a sexta ainda não foram colocadas em prática. A primeira porque o plano plurianual é feito apenas no primeiro ano de mandato de uma nova gestão, ou seja, no município de Lavras, o próximo PPA só será constituído em 2021; e a sexta pois, para buscar recursos destinados a uma ação, necessariamente ela precisa estar prevista nas peças orçamentárias.

Por outro lado, o projeto já está sendo ampliado para dois outros bairros, com dois núcleos presentes nas Escolas Municipais Itália Cautieiro Franco (CAIC) e José Luiz de Mesquita. E a terceira, quarta e quinta intervenções foram agregadas na criação de um instituto, denominado "Sete Gerações", que buscará parcerias para proporcionar, no contraturno escolar, cursos diversos aos alunos, reforço escolar e atividades esportivas diferenciadas.

Foi possível perceber, nesse retorno ao campo, que a realidade anterior, percebida durante a pesquisa (baixo número de alunos, desmotivação de participantes e professores, e ausência das famílias, por exemplo), está sofrendo alterações significativas. O número de alunos atendidos aumentou; as famílias estão mais próximas; e a criação do instituto está demonstrando a seriedade dos envolvidos, o que amplia a confiança das pessoas nessa ação.

Essas mudanças, juntamente com a transformação dessa ação em política pública, possibilitarão o surgimento de uma nova realidade na comunidade do bairro, antes nunca percebida, que ampliará os recursos disponíveis para a ação, a credibilidade do projeto e, com isso, o aumento das parcerias e da visibilidade de Lavras, que demonstrará o seu compromisso e interesse por ações empreendedoras como essa.

Além disso, nessa articulação entre ações empreendedoras e políticas públicas, poderão surgir grandes talentos no basquete, levando o município a despontar novamente no cenário esportivo, ou mesmo em outras modalidades, com a ampliação das atividades esportivas. Essa articulação também se mostra relevante, ao demonstrar a preocupação da gestão pública em cumprir a sua responsabilidade social perante a população. 


\section{CONSIDERAÇÕES FINAIS}

O maior fundamento de uma investigação científica está nas contribuições que seus resultados proporcionam. Nesse sentido, espera-se que os preceitos teóricos abordados e que a pesquisa empírica desenvolvida possam trazer contribuições relevantes à gestão pública local e para o desenvolvimento de novas pesquisas sobre o assunto, tendo relevância teórica, empírica, metodológica e impacto social.

Em termos práticos e, respondendo à questão de pesquisa, verificou-se que o município de Lavras desenvolve projetos esportivos, mas precisa criar novas políticas públicas para incentivar o esporte na cidade, de maneira mais efetiva. Dentre esses projetos, foi encontrada uma ação empreendedora, conhecida como "Arremesso para um Novo Horizonte", que, embora não seja uma política propriamente dita, é uma ação que envolve o poder público, de modo particular, sem nele ter se originado. Por isso, para que o esporte volte a se destacar na história da cidade mineira, é preciso que o poder executivo articule melhor as políticas públicas, incentivando as práticas esportivas e as ações empreendedoras no esporte.

Quanto às contribuições teóricas, discutiu-se sobre o conceito de políticas públicas e de ações empreendedoras, o que possibilitou a criação de um framework e, consequentemente, a explanação sobre tais concepções. É importante destacar que o conceito de ações empreendedoras ainda não está consolidado na literatura, especialmente quando se volta a caracterizar seus aspectos na administração pública. No desenvolvimento da pesquisa, isso foi um dificultador para a construção da base teórica, mas, por outro lado, possibilitou a discussão sobre a natureza dessas ações e, assim, contribuiu para ampliar seu significado e definir o seu conceito no setor público.

Outra contribuição significativa foi a construção das características das ações empreendedoras dentro da conceitualização do empreendedorismo, como uma ramificação desse fenômeno mundial e não como algo novo, conceitualmente desprendido de sua origem. Nesse sentido, o framework construído foi relevante para as análises e as inferências de pesquisa, e poderá auxiliar outros pesquisadores que estejam abordando a temática. Além disso, trata-se de uma explanação didática, que pode amparar os gestores públicos na construção de políticas públicas empreendedoras.

O caso apresentado do município de Lavras revela que teoria e prática precisam caminhar juntas, para que se tenha efetividade nos atos e profundidade nas ações. Contribuir financeiramente para um projeto não significa e não assegura a existência de uma ação, enquanto política pública; trata-se apenas de um incentivo. Ademais, o 
reconhecimento de uma ação pública como sendo empreendedora precisa ir além do fomento financeiro; é necessário demonstrar seus impactos sociais, para então garantir a sua previsão em termos legais. O caso em análise pode, nesse sentido, servir de aprendizagem para outros prefeitos, empreendedores públicos e secretários, no reconhecimento de ações empreendedoras em seus municípios e na definição de políticas públicas.

Ressalta-se que as pesquisas sociais não são isentas de limitações, até porque estão condicionadas ao posicionamento ontológico e epistemológico de seus pesquisadores e, por esse motivo, são passíveis de complementações em novos trabalhos. Por isso, para futuras agendas, sugere-se que: este estudo seja aplicado a outros contextos, respeitando-se as conjunturas locais; novas metodologias sejam utilizadas; e novas contribuições teóricas sejam feitas ao conceito de ações empreendedoras, no contexto público.

\section{REFERÊNCIAS}

Alford, J., \& Hughes, O. (2008). Public value pragmatism as the next phase of public management. The American Review of Public Administration, 38(2), 130-148.

Bardin, L. (2011). Análise de conteúdo. São Paulo, SP: Almeida Brasil.

Beyers, J., \& Kerremans, B. (2004). Bureaucrats, politicians, and societal interests: how is European policy making politicized? Comparative Political Studies, 37(10), 1119-1150.

Berger, P. L., \& Luckmann, T. (2010). A construção social da realidade. Lisboa: Dinalivro Edições.

Bernardes, A. G., Yamaji, B. H. S., \& Guedes, D. P. (2015). Motivos para prática de esporte em idades jovens: um estudo de revisão. Motricidade, 11(2), 163-173.

Bickel, E. A., Marques, M. G., \& Santos, G. A. D. (2012). Esporte e sociedade: a construção de valores na prática esportiva em projetos sociais. EFDeportes. com [revista digital], 17, 171.

Borges, D. A. H., \& Cappelle, M. C. A. (2018, outubro). O papel dos burocratas de colarinho branco, de nível médio e nível de rua na ação empreendedora pública. In: Anais do Encontro da ANPAD, Curitiba, PR. 42.

Boszczowski, A. K., \& Teixeira, R. M. (2012). O empreendedorismo sustentável e o processo empreendedor: em busca de oportunidades de novos negócios como solução para problemas sociais e ambientais. Revista Economia \& Gestão, 12(29), 141-168.

Bresser-Pereira, L. C. (2010). Democracia, estado social e reforma gerencial. Revista de Administração de Empresas, 50(1), 112-116. 
Brito, M. D. S. D. C. (2012). Basquete: socialização e integração do esporte, através da visão dos professores de educação física do ensino fundamental da Escola Estadual Dr. Coaracy Nunes. (Monografia). Universidade de Brasília, Macapá, AP, Brasil.

Burrell, G., \& Morgan, G. (1979). Sociological paradigms and organizational analysis. London: Heinemann Educational Books.

Constituição Federal, de 5 de outubro de 1988. (1988). Constituição da República Federativa do Brasil de 1988 Brasília, DF. Recuperado de http://www.planalto.gov.br/ccivil_03/Constituicao/Constituicao.htm.

Cunha, C. V., Silva, M. V., \& Yamaguchi, N. M. (2011). Empreendedorismo: Histórias que motivam, despertam e encantam. Anuário da Produção Acadêmica Docente, 5(12), 165-182.

Diefenbach, F. E. (2011). Entrepreneurship in the Public Sector (Dissertação de Mestrado). University of St. Gallen, Suiça.

Dresch, A., Pacheco Lacerda, D., \& Cauchick Miguel, P. A. (2015). Uma análise distintiva entre o estudo de caso, a pesquisa-ação e a design science research. Revista Brasileira de Gestão de Negócios, 17(56), 1116-1133.

Eiras, S. B., Silva, W. H. A., Souza, D. L., \& Vendruscolo, R. (2010). Fatores de adesão e manutenção da prática de atividade física por parte de idosos. Revista Brasileira de Ciências do Esporte, 31(2), 75-89.

Gomes, A. F. (2010). Ação empreendedora e relações de gênero: um estudo multicasos na cidade de Vitória da Conquista, Bahia (Tese de Doutorado). Universidade Federal de Lavras, Lavras, MG, Brasil.

Gomes, A. F., Lima, J. B., \& Cappelle, M. C. A. (2013). Do empreendedorismo à noção de ações empreendedoras: reflexões teóricas. Revista Alcance, 20(2), 203-220.

Hofling, E. D. (2001). Estado e políticas (públicas) sociais. Cadernos Cedes 21(55), 3041.

Instituto Brasileiro de Geografia e Estatística (IBGE). (2010). Censo 2010. Recuperado de http://cidades.ibge.gov.br/v4/brasil/mg/lavras/panorama.

Kim, Y. (2010). Stimulating entrepreneurial practices in the public sector: the roles of organizational characteristics. Administration \& Society, 42(7), 780-814.

Lima, J. B. (2010). Ações empreendedoras e práticas da pesquisa em empreendedorismo. In Empreendedorismo e estratégia de empresas de pequeno porte - 3Es2Ps. Curitiba: Champagnat - Editora PUC PR.

Lotta, G. S. (2012). O papel das burocracias do nível da rua na implementação de políticas públicas: entre o controle e a discricionariedade. In: Implementação de Políticas Públicas: Teoria e Prática (pp. 20-39). Belo Horizonte, BH: PUC Minas.

Meirelles, M., \& Paixão, M. R. (2003). Teorias da administração: clássicas e modernas. São Paulo: Futura. 
Ministério do Desenvolvimento Social e Combate à Fome. (2009). Adolescências, juventudes e socioeducativo: concepções e fundamentos. Brasília, DF: MDS.

Monllor, J., \& Murphy, P. J. (2017). Natural disasters, entrepreneurship, and creation after destruction: A conceptual approach. International Journal of Entrepreneurial Behavior \& Research, 23(4), 618-637.

Nascimento, P. O. (2018). A ação empreendedora na gestão pública escolar (Dissertação de Mestrado). Universidade Federal de Lavras, Lavras, MG, Brasil.

Nogueira, V. M. R. (2001). Estado de Bem-estar Social - origens e desenvolvimento. Revista Katálysis, (5), 89-103.

Paiva Júnior, F. G. (2004). O empreendedorismo na ação de empreender: uma análise sob o enfoque da fenomenologia sociológica de Alfred Schütz. (Tese de Doutorado). Universidade Federal de Minas Gerais, Belo Horizonte, MG, Brasil.

Paiva Júnior, F. G. de, \& Mello, S. C. B. (2009). O papel da ação empreendedora no cenário das empresas de base tecnológica. In: Anais do Encontro de Estudos em Estratégia, Recife, PE, 4.

Pires, R. (2012). Burocracias, gerentes e suas "histórias de implementação": narrativas do sucesso e fracasso de programas federais. In: Faria, C. A. P. (Org.), Implementação de políticas públicas: teoria e prática (pp. 182-220). Belo Horizonte, MG: Editora PUC Minas.

Ratten, V. (2011). Sport-based entrepreneurship: towards a new theory of entrepreneurship and sport management. International Entrepreneurship and Management Journal, 7(1), 57-69.

Rodrigues, M. M. A. (2010). Políticas Públicas. São Paulo, SP: Publifolha.

Rua, M. G., \& Aguiar, A. T. (2007). Análise de políticas públicas: conceitos básicos. Recuperado de http://estadoedemocracia.blogspot.com/2007/08/analise-de-politicaspublicas-conceitos.html .

Silva, B. A. R. (2017). Uma cultura escolar de esporte no Instituto Evangélico, Lavras, Minas Gerais (1893-1919). Revista Brasileira de História da Educação, 17(2[45]), 56-82.

Silva, C. A. F., Terra, B. R. C., \& Votre, S. J. (2006). O modelo da hélice tríplice e o papel da educação física, do esporte e do lazer no desenvolvimento local. Revista Brasileira de Ciências do Esporte, 28(1), 167-183.

Silva, C. A., Valadares, J. L., \& Andrade, D. M. (2016). Ações empreendedoras na gestão pública: análise do Programa Crédito Solidário (PCS) em um município do sul de Minas Gerais. Revista Eletrônica de Ciência Administrativa, 15(1), 25-39.

Sobral, F., \& Peci, A. (2013). Administração: teoria e prática no contexto brasileiro. São Paulo, SP: Pearson Prentice Hall. 
Sousa, J. L., Paiva Junior, F. G., \& Lira, Z. B. (2010). A abordagem multidimensional do empreendedorismo no setor público: o caso da ação empreendedora da fundação Joaquim Nabuco. Gestão \& Planejamento - G\&P, 11(2), 337-354.

Souto, R. C. C. (2006). Parcerias público-privadas: reflexão sobre o instituto no direito brasileiro (Dissertação de Mestrado). Pontifícia Universidade Católica de Minas Gerais, Belo Horizonte, MG, Brasil.

Souza, C. (2006). Políticas públicas: uma revisão da literatura. Sociologias, 8(16), 20-45.

Spedale, S., \& Watson, T. J. (2014). The emergence of entrepreneurial action: At the crossroads between institutional logics and individual life-orientation. International Small Business Journal, 32(7), 759-776.

Thiollent, M. (2003). Metodologia da pesquisa-ação. São Paulo, SP: Cortez.

Tubino, M. J. G. (2010). Estudos brasileiros sobre o esporte: ênfase no esporteeducação. Maringá: Eduem.

Valadares, J. L., Emmendoerfer, M. L., Alves, R. C. M., \& Morais, M. C. A. (2012). O fenômeno do empreendedorismo público: um ensaio sobre a aplicabilidade desse construto na administração pública brasileira. In Anais do Encontro da ANPAD, Rio de Janeiro, RJ, 36.

Viswanathan, M., Echambadi, R., Venugopal, S., \& Sridharan, S. (2014). Subsistence entrepreneurship, value creation, and community exchange systems: A social capital explanation. Journal of Macromarketing, 34(2), 213-226.

Zen, A. C., \& Fracasso, E. M. (2008). Quem é o empreendedor? As implicações de três revoluções tecnológicas na construção do termo empreendedor. Revista de Administração Mackenzie, 9(8), 135-150.

\section{AGRADECIMENTOS}

O presente trabalho foi realizado com apoio da Coordenação de Aperfeiçoamento de Pessoal de Nível Superior - Brasil (CAPES) - Código de Financiamento 001. 